\title{
Creating and Deploying USB Port Covers at Hudson County Community College
}

\section{ABSTRACT}

In 2016, Hudson County (NJ) Community College (HCCC) deployed several wireless keyboards and mice with its iMac computers. Shortly after deployment, library staff found that each device's required USB receiver (a.k.a. dongle) would disappear frequently. As a result, HCCC library staff developed and deployed 3D printed port covers to enclose these dongles. This, for a time, proved very successful in preventing the issue. This article will discuss the development of these port covers, their deployment, and what worked and did not work about the project.

\section{INTRODUCTION}

3D printing was invented in the 1980s but remained a niche product until emerging as a mainstream technology beginning in 2009. It has been speculated that the growth in popularity was due to several factors, most notably the expiration of patents on technologies such as fused deposition modeling. ${ }^{1}$ The expiration of this patent led to the emergence of several new companies such as MakerBot, which developed and released lower priced 3D printers in an effort to popularize 3D printing. ${ }^{2}$ Nevertheless, early $3 \mathrm{D}$ printers were still more expensive than most individual consumers could afford. As with laser printers in the 1980s, many libraries combined their role in the growing makerspace movement with their community purchasing power to bring this new technology to libraries across the United States. ${ }^{3}$ Libraries thus became focal points in the nascent consumer 3D printing movement, frequently providing both training and access to supplies and equipment. As the popularity of 3D printing grew, new communities of 3D printing users emerged and began to design and share artwork and practical objects created with 3D printing technology, often via communities like Thingiverse and Shapeways.

\section{D PRINTING AT HUDSON COUNTY COMMUNITY COLLEGE}

In August 2014, the Hudson County (NJ) Community College (HCCC) Library moved into a larger facility, nearly doubling its square footage. At this time, many libraries were beginning to open makerspaces, which are facilities for collaboration where the "emphasis is on creating with technology," and HCCC saw an opportunity to join this movement. ${ }^{4}$ Given the results of student feedback surveys, and the observed popularity of 3D printing in public libraries, HCCC librarians sought to purchase a 3D printer as a signature technology for the new makerspace. To support the new makerspace, the library's staff implemented a series of workshops to teach students how to use the 3D printer and create their own projects. In addition, when the makerspace was not in use, the library's administration allowed staff to experiment with the 3D printer, as well as all

Lotta Sanchez (lsanchez@hccc.edu) is Library Associate - Technology, Hudson County Community College. John DeLooper (john.delooper@lehman.cuny.edu) is Web Services - Online Learning Librarian, Lehman College, City University of New York. 
technologies housed in the makerspace, to allow them to better understand and promote these tools.

\section{ABOUT HUDSON COUNTY COMMUNITY COLLEGE}

As per its 2017-18 HCCC Factbook, HCCC is an urban institution "offering courses and classes in a wide variety of disciplines and studies in one of the most densely populated and ethnically diverse areas of the United States." ${ }^{\prime 5}$ As of fall 2017, HCCC's full-time-equivalent student population is 7,712, and includes students representing "more than 90 nationalities." Many of these students hail from outside of the United States, "nearly 58 percent of whom speak a language other than English in their homes." HCCC's demographics also skew young, with students ages 20 through 29 comprising approximately 52 percent of enrolled students. More recently, HCCC has also increased its enrollment of high school students, as "the number of students under the age of 18, who are mostly enrolled through HCCC's various high school initiative programs, has more than quadrupled over the past five years." As with many other community colleges, HCCC's student body includes approximately a 6:4 ratio of female to male students.

\section{THE MAC USB DILEMMA}

As part of the move to a new facility, the library purchased several new technologies such as computers including Dell PCs and Apple iMacs (Macs). The Dell PCs came with wireless keyboards and mice, and in March 2016, the Macs were switched to wireless keyboards and mice as well because their original keyboards and mice began to break down and needed replacement. Students reported to library staff that the wireless keyboards and mice were a good investment, as they made it easier to move keyboards for better collaboration and for ease of storing backpacks and textbooks on desks. On both the Dell PCs and the Macs, the wireless keyboards and mice required the use of a small USB receiver, known as a dongle, to connect to the computer.

As the wireless keyboards were installed, several library staff members raised concerns that wireless keyboards and mice would be tempting targets for theft by patrons. Surprisingly, theft of keyboards and mice did not come to pass. Since deployment, library staff reported no incidents of theft of any keyboards or mice. However, an unexpected type of theft soon emerged. Library employees noticed that on the iMacs, the Type-A USB dongles, which were needed for the computers to receive input from the keyboards and mice, started disappearing. Staff observed that this seemed to be a problem only among the library's 18 Macs, not its 57 Dell computers, which also had wireless keyboards and wireless receivers. Anecdotal observation suggested that this phenomenon emerged due to the Dell's dark color scheme, which obscured each computer's USB ports, and rendered the dongles inconspicuous. In contrast, the iMacs had sleek aluminum finishes, on which the dongles were more visible, and seemed to be perceived by students as flash drives (see figures 1-5). 


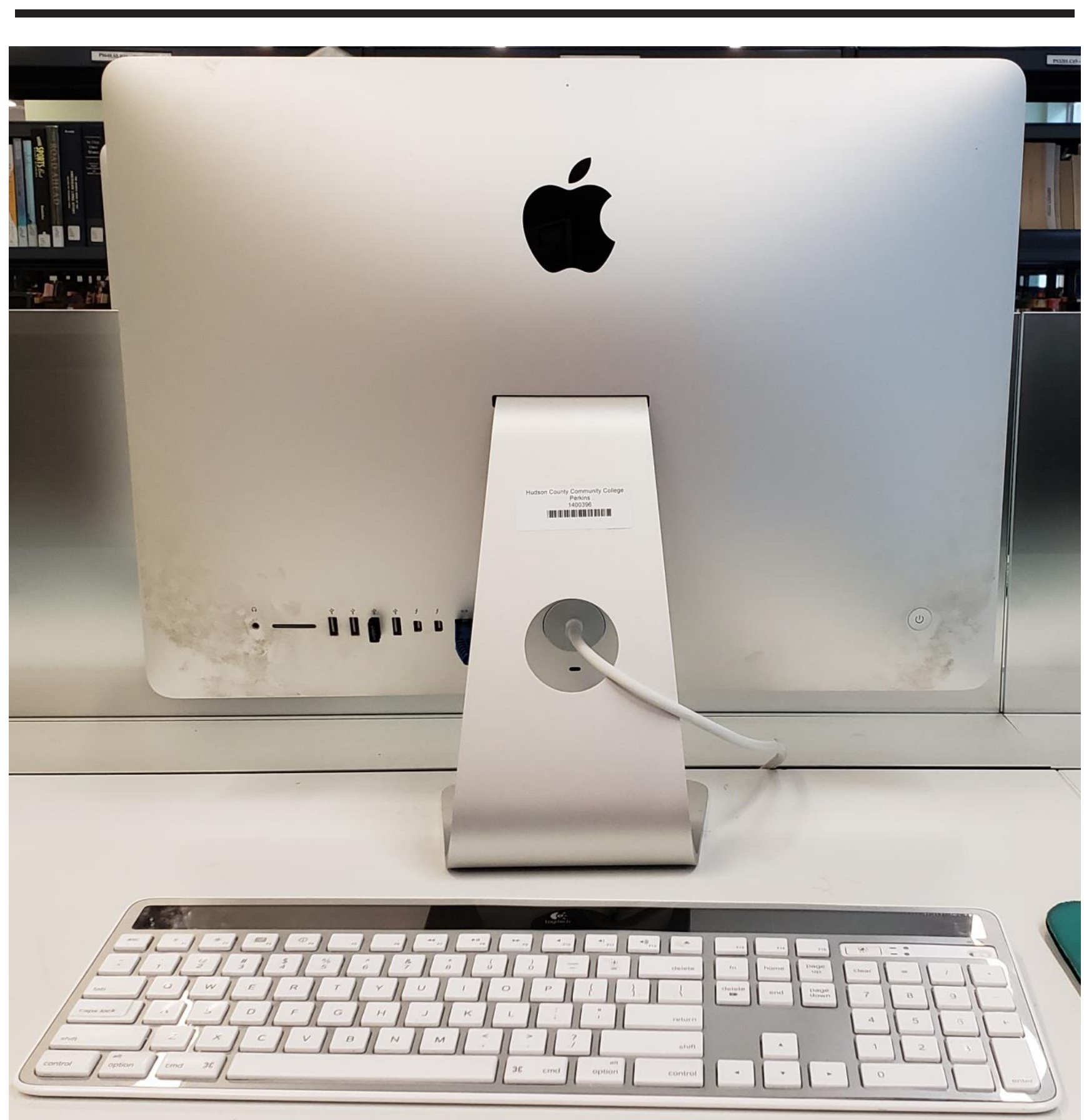

Figure 1. HCCC iMac (back with dongle shown). 


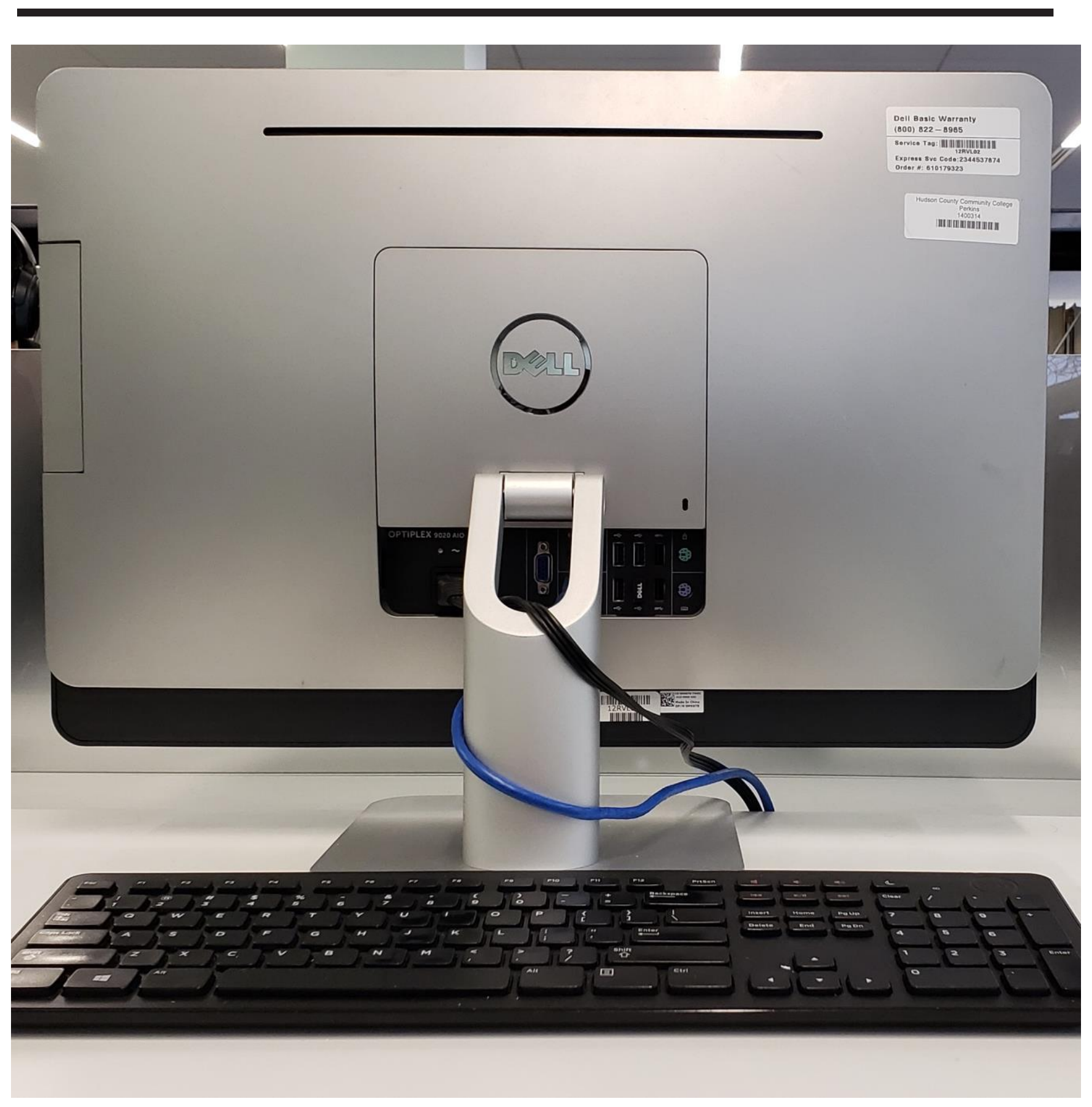

Figure 2. HCCC Dell PC (back with dongle shown). 


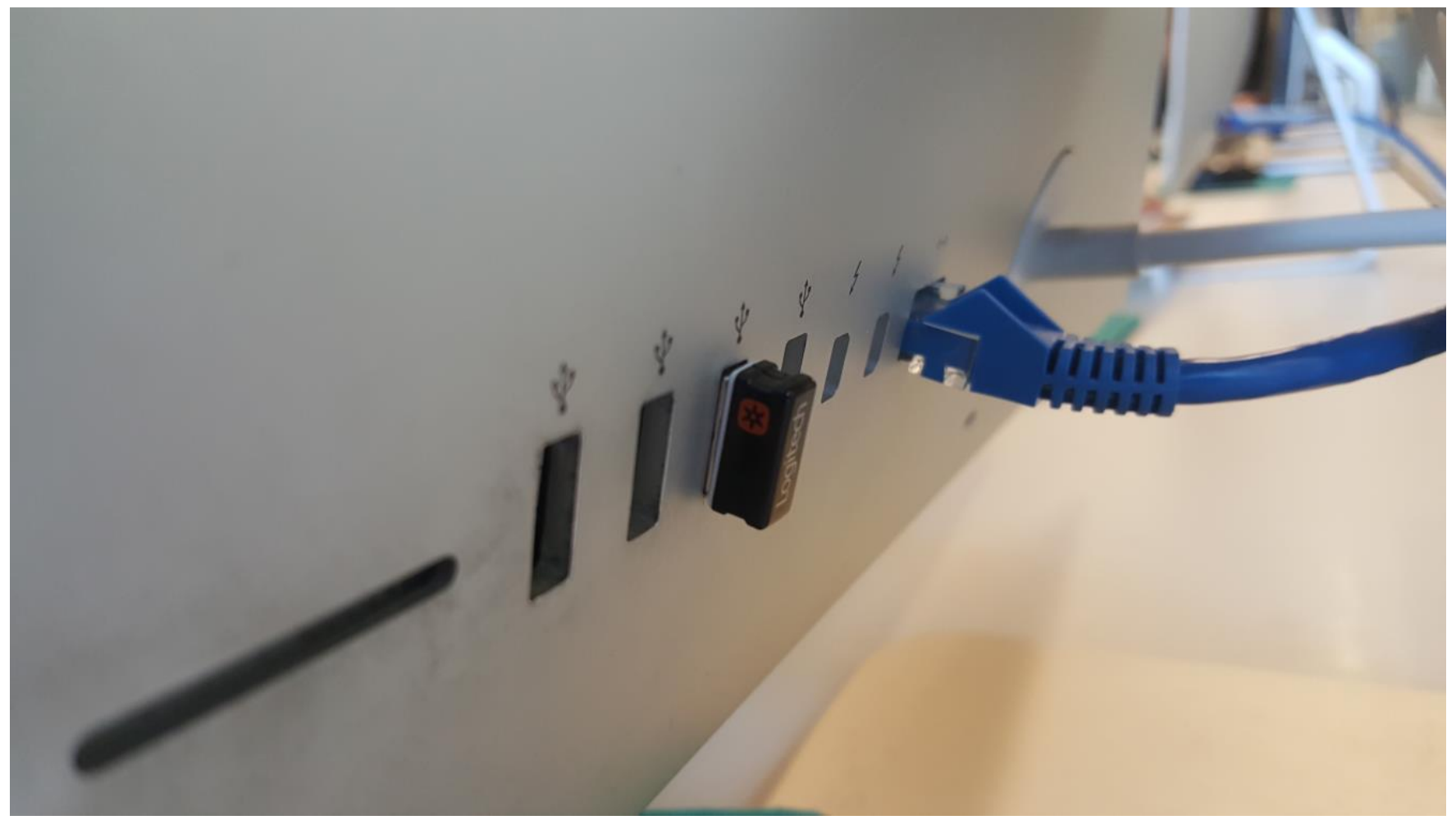

Figure 3. HCCC iMac with USB dongle closeup.

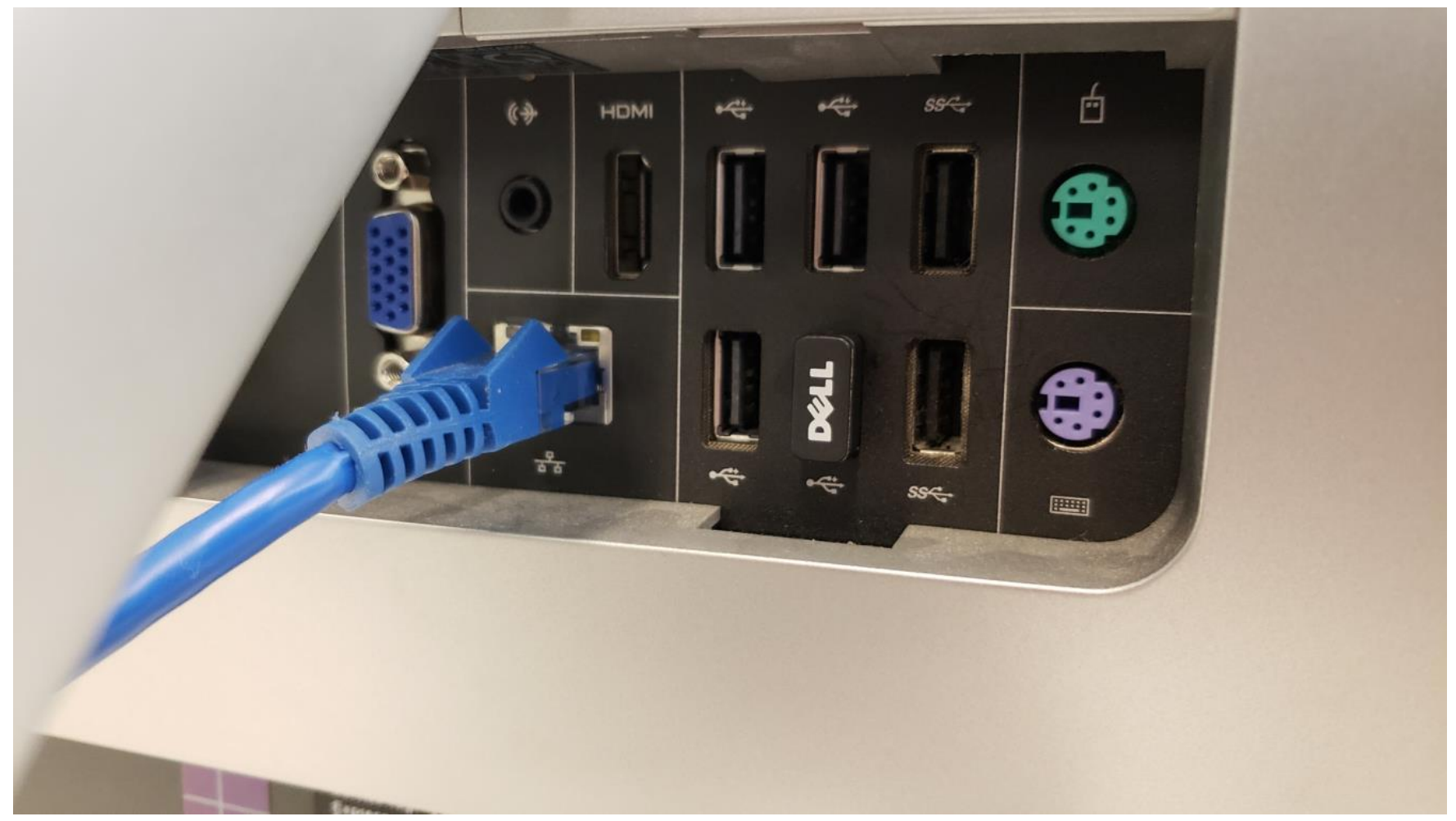

Figure 4. HCCC PC with USB dongle closeup. 


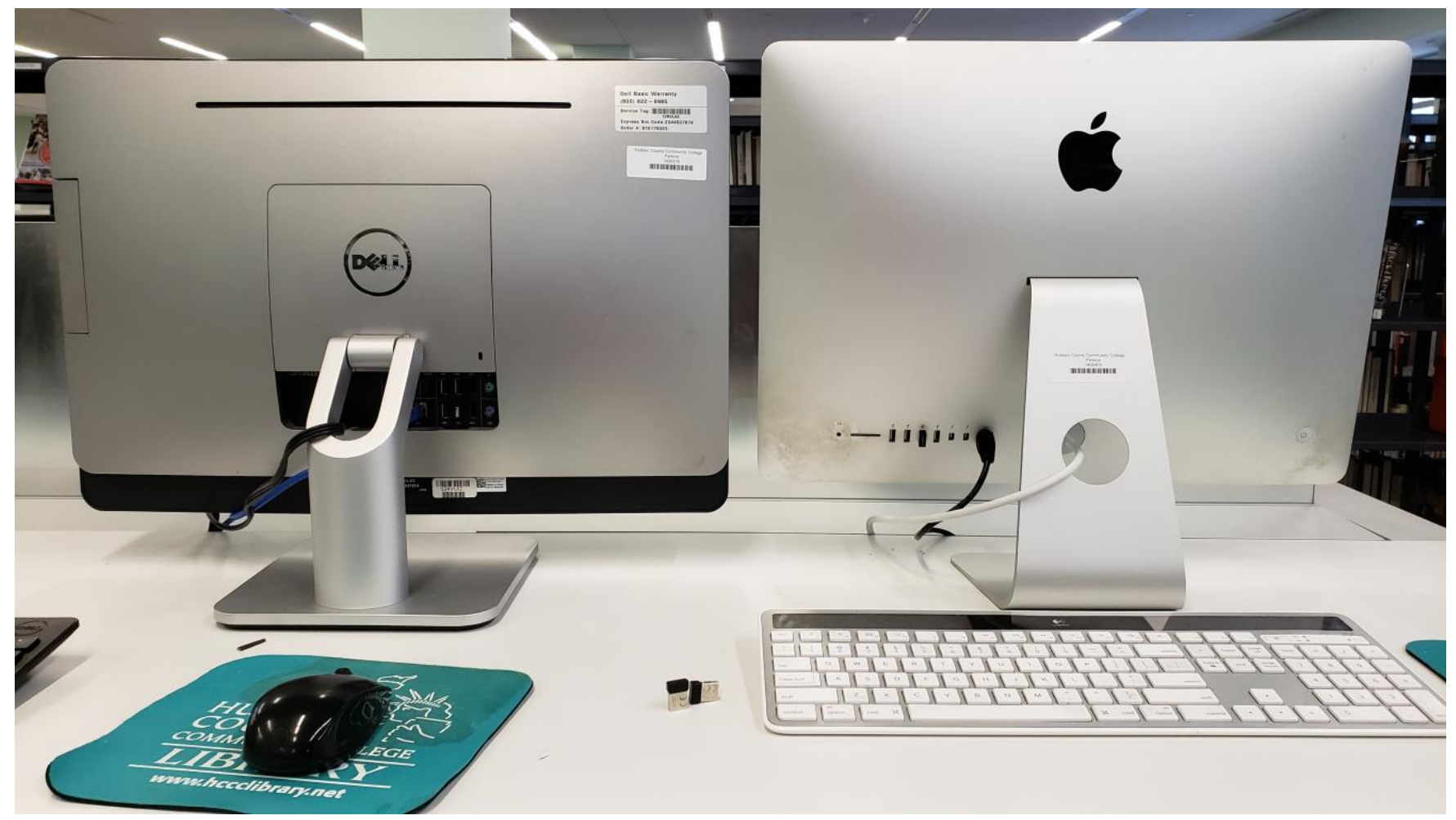

Figure 5. Comparison of Mac and PC USB ports.

These perceptions were confirmed as students started visiting service points with dongles from the Macs and turning them in to library staff as "lost flash drives." As there was frequently a lag between when a dongle was turned over to staff and the device's initial disappearance, students began to report frustration that they would try to use a Mac and find that the mouse and keyboard could not communicate with the computer. This would cause them to assume that the Mac was broken, and library staff would respond by taking the computer out of service until a tech could examine it, often several hours or even days later depending on staffing. During the first semester that these keyboards and mice were deployed, the library found that almost every USB receiver was lost or stolen. This resulted in over $\$ 300$ of unplanned expenses. In addition, library staff spent dozens of hours inspecting the iMacs after students reported non-functioning keyboards, determining what issue was occurring, ordering replacement parts, and connecting new dongles, a process also referred to as "pairing."

To address this problem, HCCC's director of library technology sought solutions from the library's technology staff. At a staff meeting in the spring 2016 semester, most of the members of the technology unit suggested that the library address the disappearing dongle issue by purchasing new wired keyboards and mice. The director of the technology unit felt that this was a premature solution to the issue, as he and the library administration preferred a solution that allowed the library to continue to use the wireless keyboards and mice, which were both costly and requested by the institution's student community. During this meeting, the idea of finding port covers for the dongles arose, and one of the library's technology associates suggested using the library's 3D printer to create a cover that inserts into one Type A USB port and would cover the dongle in the adjacent slot. The library's technology director asked her to create a prototype, and the technology associate began work on creating this port cover. 


\section{METHODOLOGY}

To create the 3D-printed port cover, the technology associate began with an online search of the 3D-printing community Thingiverse, looking to see if any other 3D port covers already existed. She hoped to find an existing port cover that was both functional and easy to manufacture-in other words, quick to print, since the library's MakerBot Replicator often took hours to print intricate designs and frequently jammed, due to an extruder design flaw that was common to fifth generation Replicator printers. ${ }^{6}$ A Thingiverse search found several varieties of port covers, but each was designed solely to occupy a port in order to prevent dust or corrosion, not to cover or hide dongles or other peripherals. Since none of the existing designs adequately met the library's needs, the technology associate created her own design using TinkerCAD, a web-based computer aided design (CAD) program (see figure 6).

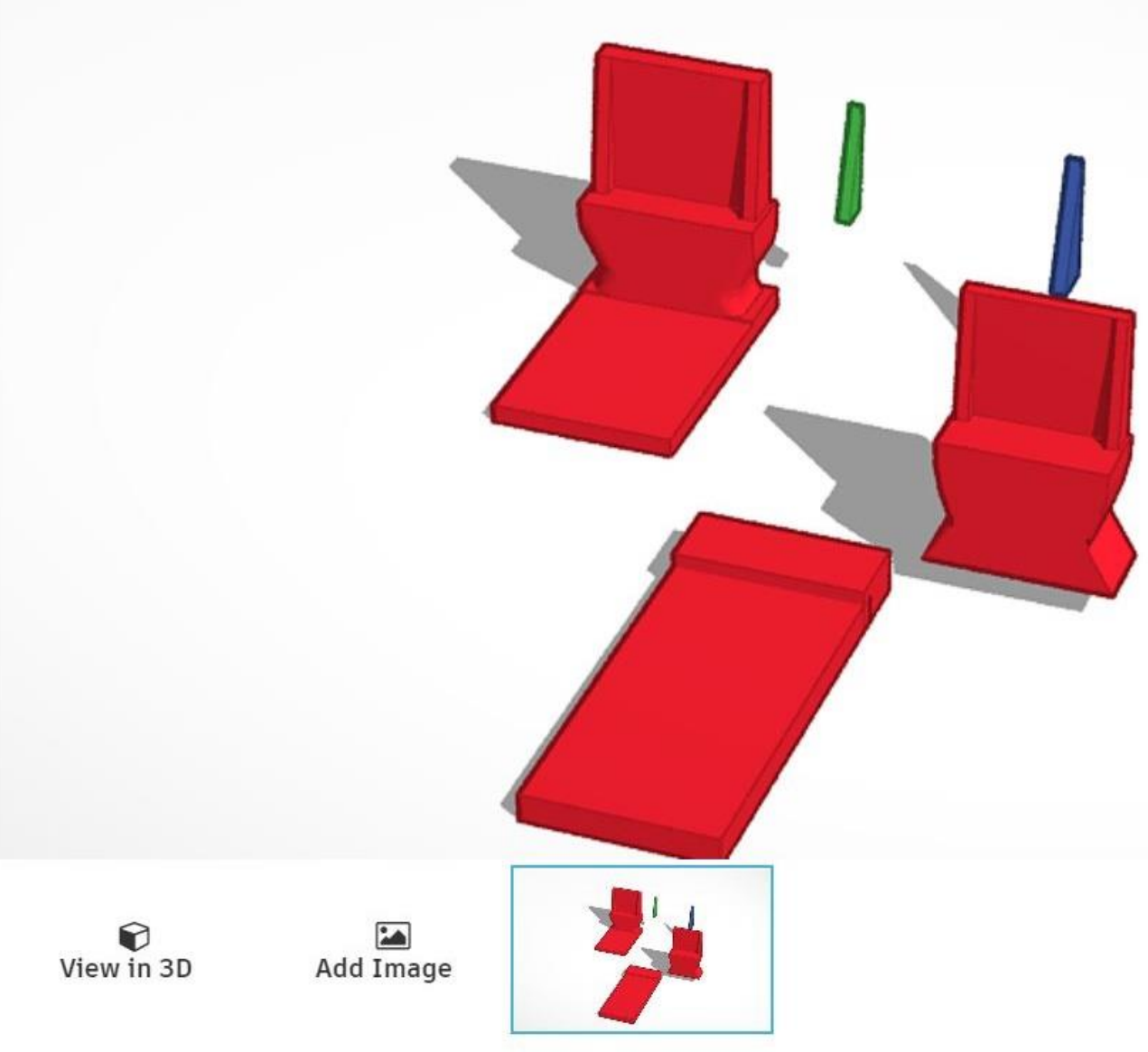

Figure 6. Picture of port cover design in TinkerCAD.

Since each of HCCC's iMac computers contained four Type A ports, students would often attach other peripherals such as phone charge/sync cables or flash drives. Therefore, the port cover needed to be small enough to allow room for peripherals. The technology associate thus designed a cover that would not hinder students who wanted to insert their USB flash drives or other devices, as is depicted in figures 7-10. 


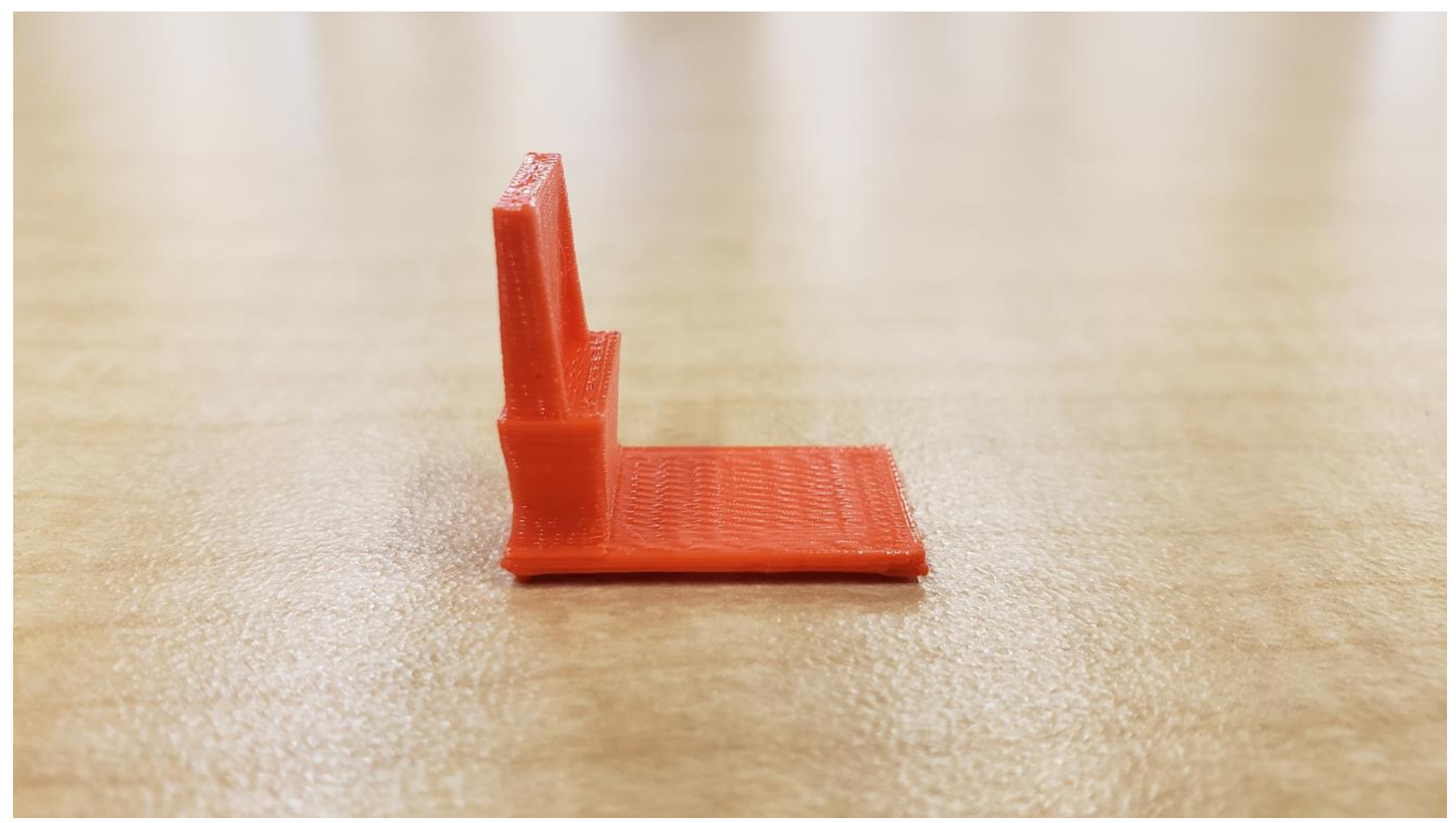

Figure 7. Closeup of port cover.

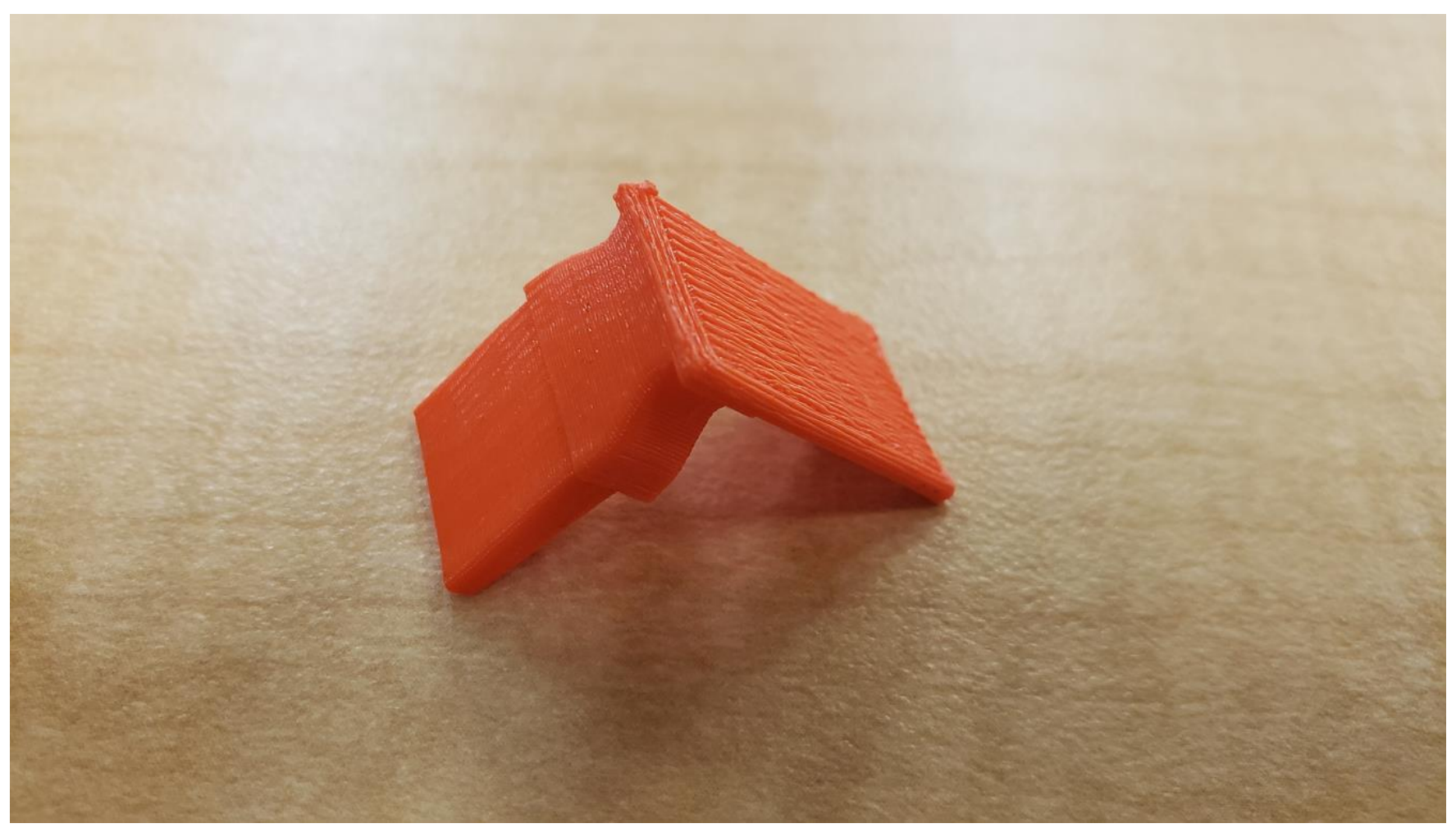

Figure 7. Alternate angle of port cover. 


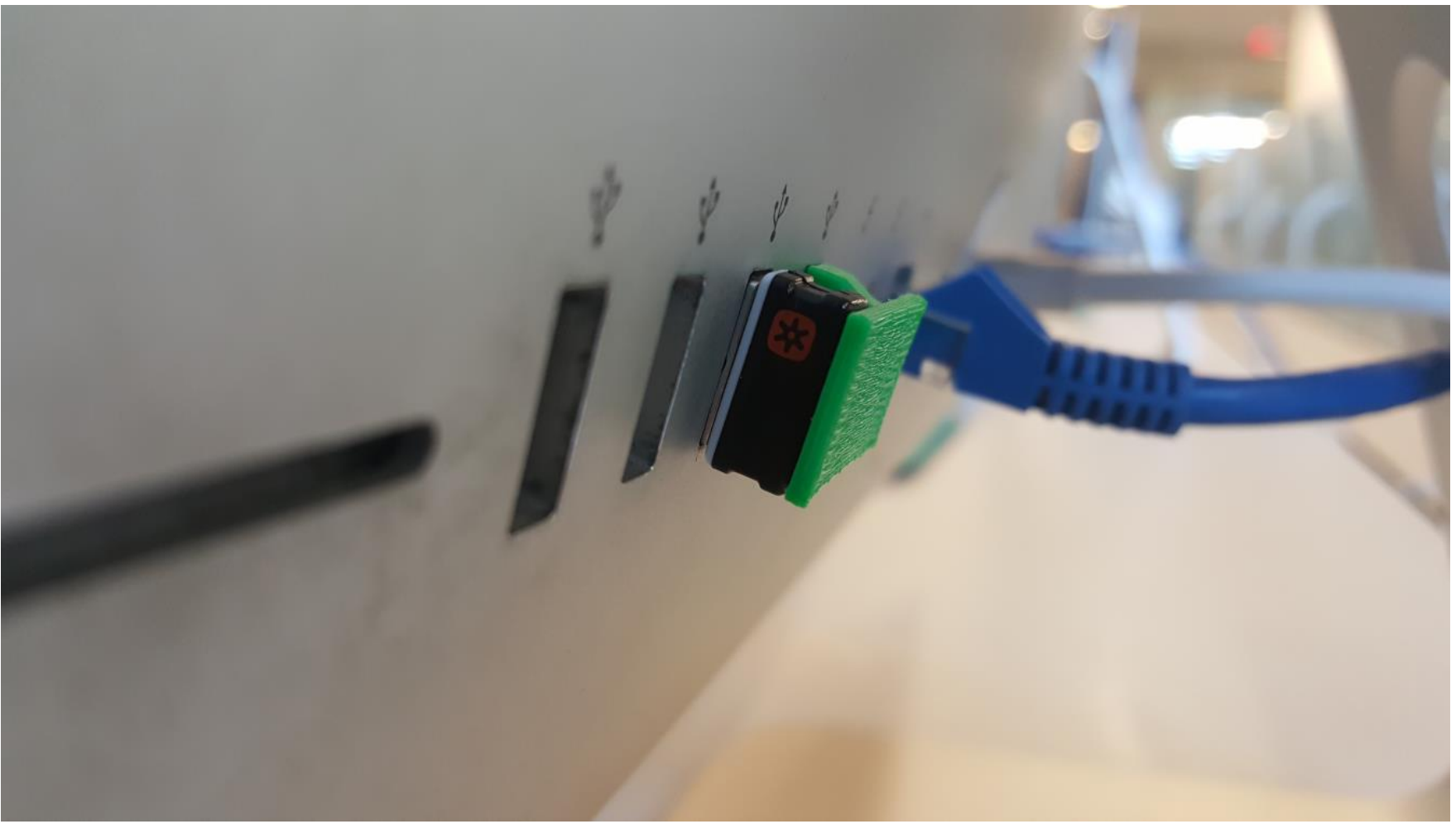

Figure 8. Picture of dongle with port cover installed.

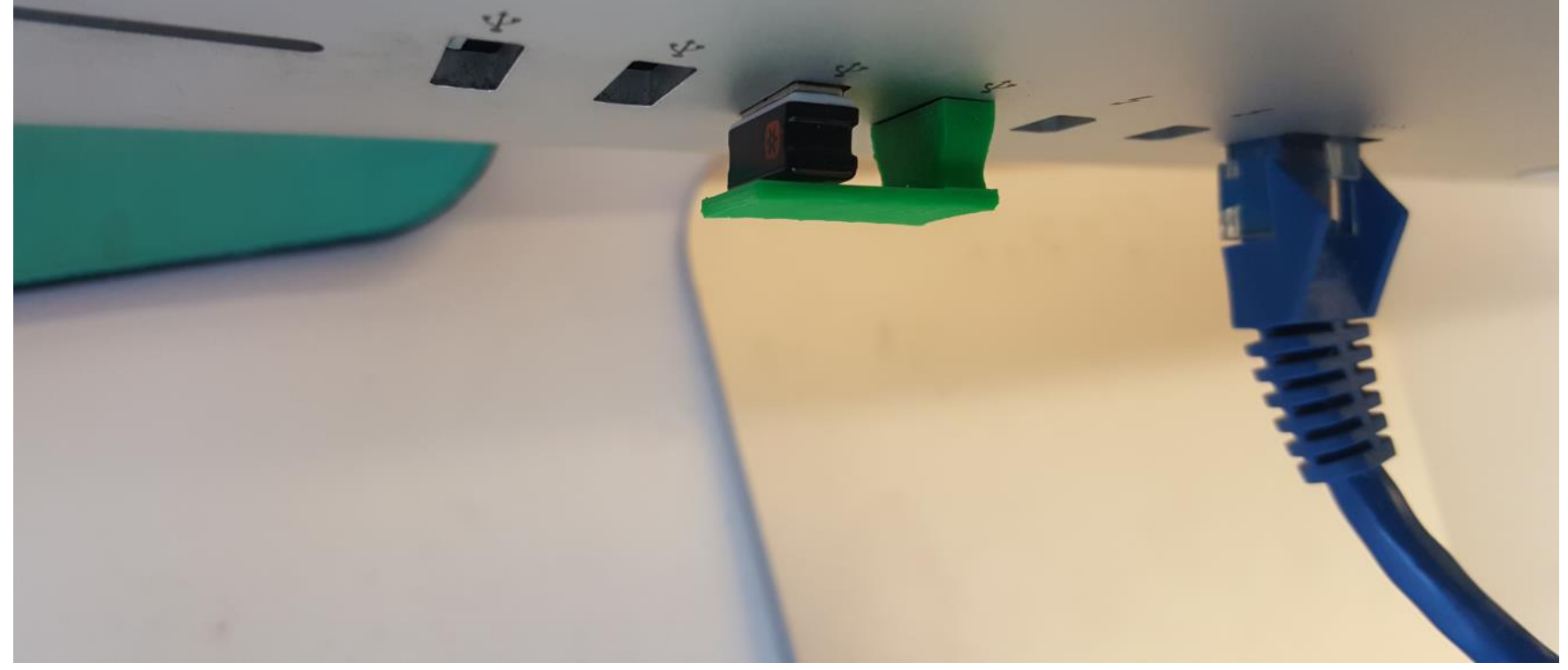

Figure 9. Port cover allowed space to utilize other USB ports for flash drives, etc. 
She then exported the TinkerCAD design as an STL (Stereolithography) file, and printed prototypes on the MakerBot Replicator using PLA filament. Finding that her initial measurements did not quite fit, she adjusted the models one millimeter at a time, and reprinted them until the fit was secure and the dongles were covered. At this point, she printed enough covers for each Mac, along with a few spares in case covers broke or wore out during normal operation.

\section{RESULTS}

At the beginning of the fall 2016 semester, the port covers were deployed to each of the library's Macs. During that semester, the technology associate monitored the effectiveness of the port covers. By the end of the semester, four port covers had disappeared, along with one dongle. At the beginning of the spring 2017 semester, the missing dongle was replaced, and replacement port covers were printed and deployed to the machines from which the port covers disappeared. Again, the success of the port cover installation project was monitored. During this period, four port covers disappeared, along with two dongles. After the spring semester, the technology associate conferred with the director of library technology, and they decided that given the relatively low cost of 3D-printer filament used to print the dongles, and the greatly reduced receiver theft rate, this was an acceptable loss. They therefore decided to continue utilizing the port covers. But, in the fall 2017 semester, five covers and each of their corresponding dongles disappeared. Then, during spring 2018 semester, all of the port covers disappeared at least once, as did the associated dongles. In total, 20 dongles were lost during that semester. The director of library technology and the technology associate conferred once again, and decided that due to this increase in theft, and a concurrent change in the college's purchasing process, the library would abandon the 3D-printed port cover experiment.

\section{ANALYSIS}

After two seemingly successful semesters, library staff were proud of the changes that resulted from deploying the port cover. Yet given the reoccurrence of the theft pattern in subsequent semesters, they started to worry that printing new port covers was not a sustainable practice. To that end, the technology associate considered several theories as to what would cause the port covers to disappear. For instance, research by Keizer, Lindenberg, and Steg found that acts of social disorder (such as graffiti or litter) will spread if not stopped promptly. ${ }^{7}$ Under this framework, it could be suggested that the library was too slow to respond to missing covers, and thus permitted the loss of the dongles due to insufficient action or maintenance. This theory seems logical since following an enrollment decline that began in fall 2016, a hiring freeze was instituted so as staff members left the institution, few positions were replaced. Indeed, as of fall 2018, HCCC's staff is 75 percent part-time and part-timers are subject to renewal or dismissal every six months. In addition, many library employees are student workers, who often leave at graduation, and other part-time staff tend to find full-time employment or leave the library for full-time work at rates that may exceed other institutions who have more permanent staff. With limited staff resources, many of the library's employees noted anecdotally that they were not able to give as much attention toward preventative maintenance on library computers as they had in prior semesters. Therefore, they did not have time to proactively monitor equipment such as port covers and dongles.

It is also possible that a novelty factor was at play. Perhaps when the covers were first deployed, the brightly colored filaments stood out on the aluminum computers, making students more likely 
to notice them and alter their behaviors accordingly. If this was the case, new students who began their coursework in subsequent semesters would not have known that port covers were an additional piece that had been added to the library's computers in response to prior issues. Following this speculation, the library's patrons who removed port covers in fall 2017 and spring 2018 might have thought they were removing damaged or nonfunctional flash drives similarly to the students who brought what they believed were lost flash drives to library staff during the spring 2016 semester.

Finally, the difference in semesters could also have been due to random chance, in which case, no staff action could have affected the rate at which port covers disappeared.

\section{CONCLUSION AND FUTURE RESEARCH}

Being unsure of which of these analyses was most correct, the technology associate had planned to learn from the sudden resurgence in thefts in several ways. She planned to experiment with adding signage about the importance of dongles and the usage of port covers, and to interview student Mac users to find out their perceptions about the port covers, as well as possible ideas and student-generated suggestions to prevent future thefts. She also considered designing and experimenting with printing more elaborate port covers to see if increased visibility or an elaborate shape would change theft rates. However, a complication arose during the 2018 and 2019 fiscal years. During this time, the college's finance office changed its purchasing procedures. First, they eliminated the library's technology budget, centralizing all technology purchases in a "pool," whose total budget was uncertain. To make purchases from this pool, departments had to create detailed needs justification and obtain approvals from four high-level executives, in addition to the preexisting procedure of obtaining quotes and getting department head and vice president approval. While the library was eventually able to obtain funds from this process, navigating the pool process typically took about six months per purchase, which meant that, in effect, replacement dongles had to come from existing supplies. In addition, the supplies budget line, which was greatly reduced due to the enrollment decline, also came under increased scrutiny, and the purchasing department began to refuse to approve the purchase of batteries. While many of the Mac keyboards were solar powered, and thus did not require batteries, all of their wireless mice, along with the wireless keyboards and mice on the Windows PCs, required the use of either AA or AAA batteries. As battery supplies dwindled, the Purchasing Department did eventually agree to allow purchase of more batteries, under the condition that the library begin going through the pools process to purchase wired keyboards and mice. In the meantime, the technology associate continues to monitor wireless dongles, reprint port covers, and swap wired keyboards from the library's spare parts inventory for wireless ones as dongles have disappeared.

The creation of 3D-printed port covers was successful at preventing equipment loss at HCCC for only two semesters before failing to fulfill that purpose. Library staff speculated about the cause of this change but were unable to make that determination with certainty before budgetary changes caused the end of the 3D-printed port cover experiment. Nevertheless, this project proved valuable to the library to better learn about 3D-printing technology, and to experiment with its practical uses in the library environment.

\section{ENDNOTES}


${ }^{1}$ Filemon Schoffer, "How Expiring Patents Are Ushering in the next Generation of 3D Printing," TechCrunch (blog), June 5, 2016, http://social.techcrunch.com/2016/05/15/how-expiringpatents-are-ushering-in-the-next-generation-of-3d-printing/.

${ }^{2}$ Christopher Mims, “3D Printing Will Explode in 2014, Thanks to the Expiration of Key Patents," Quartz (blog), July 21, 2013, https://qz.com/106483/3d-printing-will-explode-in-2014thanks-to-the-expiration-of-key-patents/.

3 Jason Griffey, “Absolutely Fab-Ulous," Library Technology Reports 48, no. 3 (April 2012): 21-24, https://journals.ala.org/index.php/ltr/article/view/4794.

${ }^{4}$ Caitlin Bagley, "What Is a Makerspace? Creativity in the Library," ALA TechSource, December 20, 2012, http://www.ala.org/tools/article/ala-techsource/what-makerspace-creativity-library.

United for Libraries, American Library Association Office for Information Technology Policy, and Public Library Association, "Progress in the Making: An Introduction to 3D Printing and Public Policy," September 2014, http://www.ala.org/advocacy/sites/ala.org.advocacy/files/content/advleg/pp/hometip3d_printing_tipsheet_version_9_Final.pdf.

${ }^{5}$ Hudson County Community College, “Fact Book 2017-2018," 2018, https://www.HCCC.edu/uploadedFiles/Pages/Explore_HCCC/Visiting_HCCC(1)/FACTBOOK\%20final\%20web\%20version.pdf.

${ }^{6}$ Adi Robertson, “MakerBot Is Replacing Its Most Ill-Fated 3D Printing Product,” The Verge (blog), January 4, 2016, https://www.theverge.com/2016/1/4/10677740/new-makerbot-smartextruder-plus-3d-printer-ces-2016.

${ }^{7}$ Kees Keizer, Siegwart Lindenberg, and Linda Steg, “The Spreading of Disorder," Science 322, no. 5908 (2008): 1681-85. 